\title{
Lipid levels in patients with rheumatoid arthritis and the effect of rituximab
}

I. Kostoglou-Athanassiou, E. Xanthakou, A. Tzanavari, A. Gkountouvas, N. Dadiras, E. Koutsika, P. Athanassiou Department of Endocrinology, Red Cross Hospital, Athens, Greece

Endocrinologist

Department of Rheumatology, St. Paul's Hospital, Thessaloniki, Greece 


\section{Introduction}

- Rheumatoid arthritis (RA) is known to be associated with cardiovascular comorbidity

- In particular, patients with RA are known to be at increased for the development of atherosclerosis

- Treatment with biological agents in RA may affect lipid levels 


\section{Aim}

- The aim was to study the effect of rituximab treatment on lipid levels in RA patients 


\section{Methods}

- In a cohort of 20 patients with RA lipid levels were studied before, 6 and 12 months after treatment with the biological agent rituximab (2x1000 $\mathrm{mg}$ i.v. infusions 2 wks apart) at baseline, 6 and 12 months later

- All patients fulfilled the 2010 ACR/EULAR criteria for RA

- Total cholesterol, HDL, LDL cholesterol and triglyceride levels were measured at baseline, 6 and 12 months later 


\section{Results}

- At baseline total cholesterol was $207.41 \pm 8.33 \mathrm{mg} / \mathrm{dl}$ (meantSEM), 6 months and 12 months later increasing to $218.27 \pm 7.02$ and $226.12 \pm 8.71 \mathrm{mg} / \mathrm{dl}$, respectively $(p<0.001$, Student's t test)

- At baseline HDL cholesterol was $59.17 \pm 3.31 \mathrm{mg} / \mathrm{dl}, 6$ and 12 months later increasing to $66.05 \pm 3.49$ and $58.81 \pm 3.04$ $\mathrm{mg} / \mathrm{dl}$, respectively $(\mathrm{p}<0.001)$

- At baseline LDL cholesterol was $122.89 \pm 8.96 \mathrm{mg} / \mathrm{dl}, 6$ and 12 months later increasing to $124.58 \pm 5.61$ and $141,56 \pm 7.95$ $\mathrm{mg} / \mathrm{dl}$, respectively $(\mathrm{p}<0.001)$

- At baseline triglyceride levels were $138,50 \pm 13.91 \mathrm{mg} / \mathrm{dl}, 6$ and 12 months later decreasing to $122.55 \pm 10.52$ and $118.65 \pm 9.91 \mathrm{mg} / \mathrm{dl}$, respectively $(p<0.001)$ 


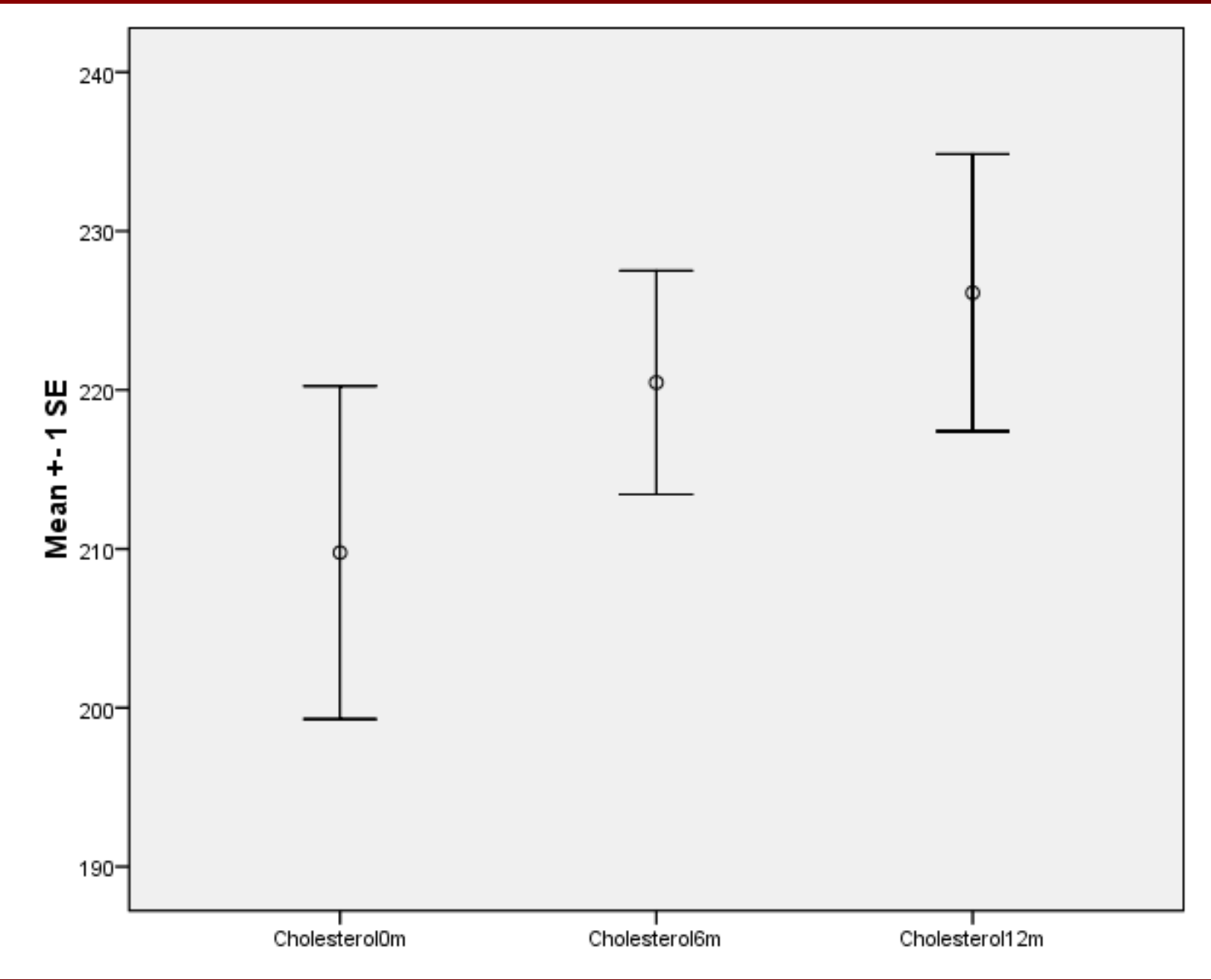

Total cholesterol in patients with RA before, 6 and 12 months after the administration of rituximab 


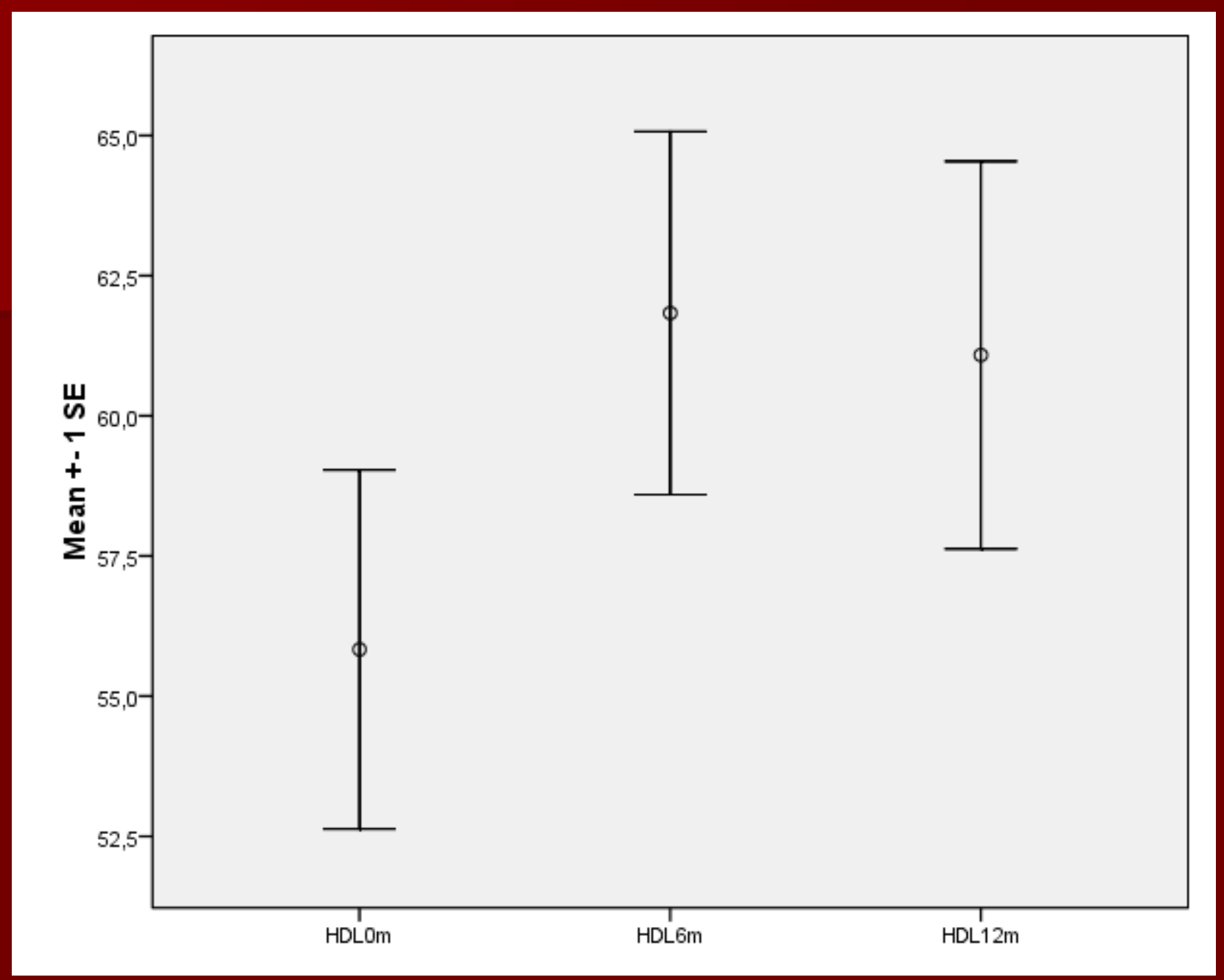

HDL cholesterol in patients with RA before, 6 and 12 months after the administration of rituximab 


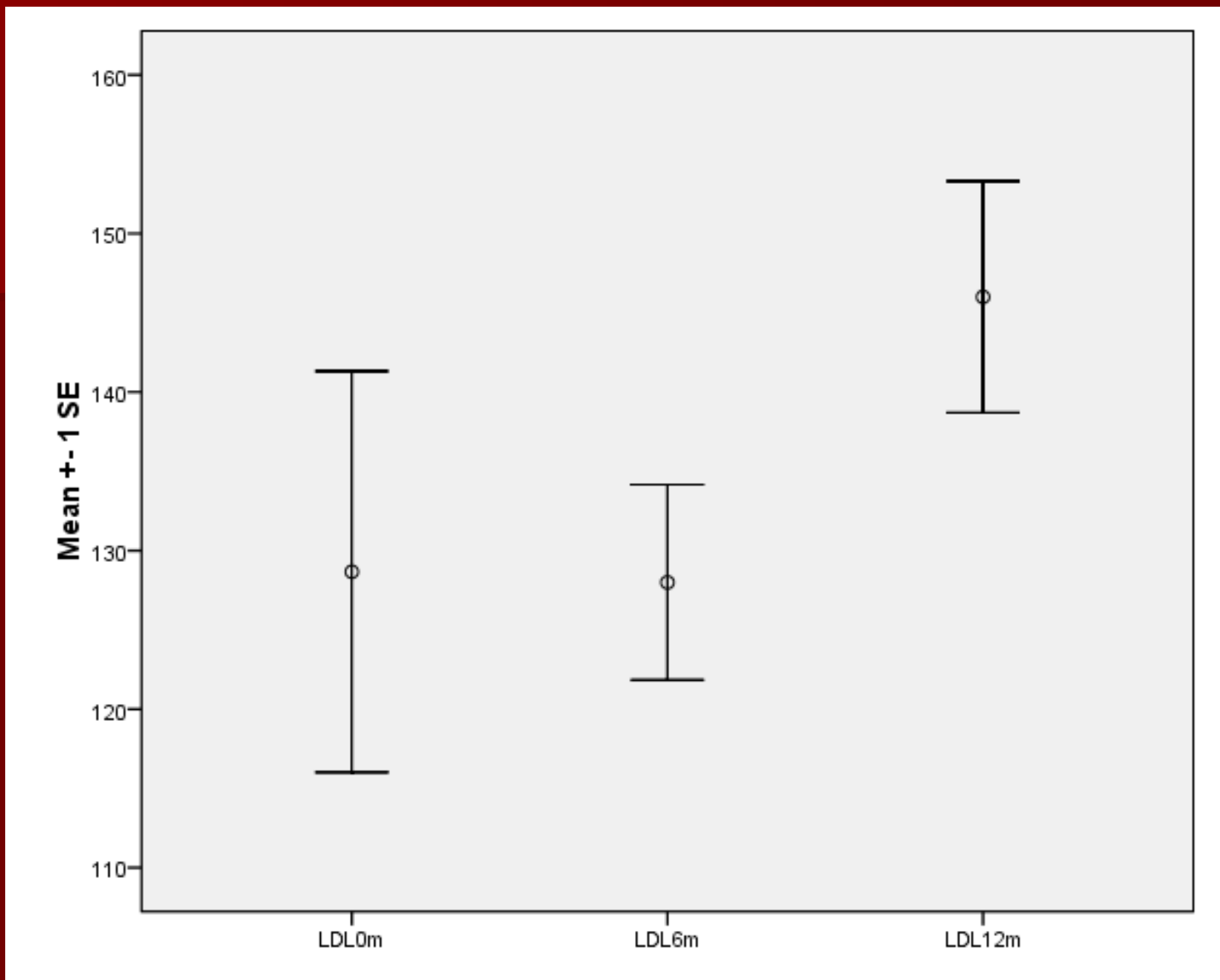

LDL cholesterol in patients with RA before, 6 and 12 months after the administration of rituximab 


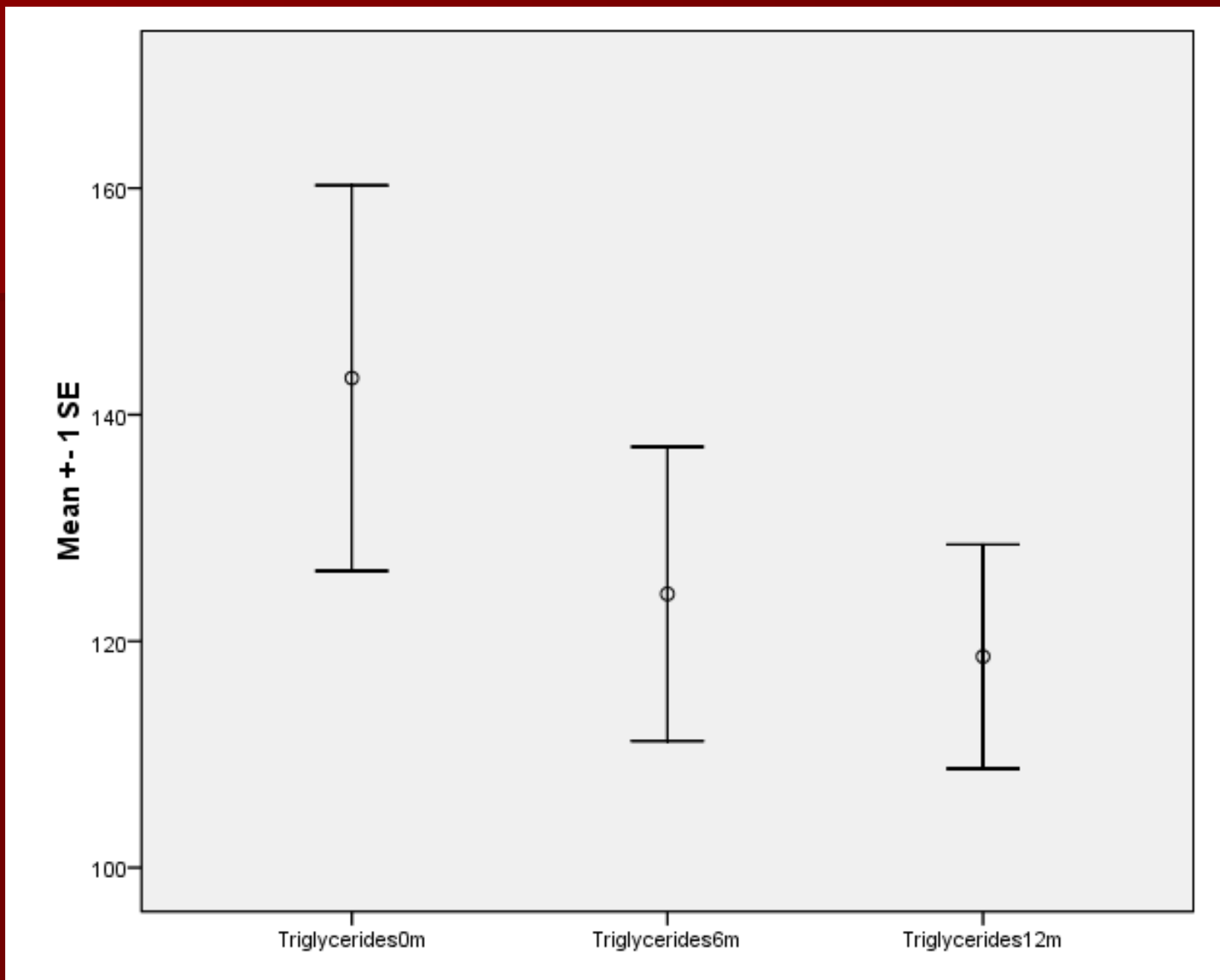

Triglyceride levels in patients with RA before, 6 and 12 months after the administration of rituximab 


\section{Conclusions}

- Treatment with the biological agent rituximab in $R A$ resulted in an increase in total cholesterol, paralleled by an increase in HDL cholesterol, LDL cholesterol, while triglyceride levels decreased

- The adverse effect on total cholesterol levels may be counteracted by the parallel increase in HDL thus conferring a beneficial effect on the patients as far as cardiovascular risk is concerned

- These findings have therapeutic implications as the effect of rituximab on lipid levels may render systematic treatment with statins necessary in rheumatoid arthritis 